Covered in: Web of Sciences (WOS); EBSCO; ERIH+; Google Scholar; Index Copernicus; Ideas RePeC; Econpapers; Socionet; CEEOL; Ulrich ProQuest; Cabell, Journalseek; Scipio; Philpapers; SHERPA/RoMEO repositories; KVK; WorldCat; CrossRef; CrossCheck

2018, Volume 10, Issue 1, pages: 10-19 | doi: https://doi.org/10.18662/rrem/12

\section{Issues of Training \\ Evaluation at Javelin Throwers}

\section{Margareta ANTON $^{1}$}

${ }^{1}$ Ecological University, Bucharest, Romania, margaretabosancenu@yahoo.com
Abstract: Starting with the assumption that if the means used during the training of the high performing javelin throwers are the suitable ones, then, the competition results will be the echo of the consigned effort.The objective of this research is mainly to correlate the foremost means that were used with the result from the contest and to supervise the physical training before the reference competition. The methods used to investigate the utility were the pedagogic observation,the method of measurements and tests, the statistical processing of the data and the the graphic interpretation of the resulted data. Four of the best javelin throwers in Romania were monitored during a centralized cantonment, with the software „Polar Team” and the results of the control tests during a 3-month training session together with the final competiton result were taken into account. The usage of the software in training may offer the throwers information about the stage of their training and the biological echo of the effort they provided. Regarding the training means used, some of them may be redundant but others can be quite relevant in the obtaining of the sport result: dumbbell snatch, long jump without momentum.Putting aside these means would lead to a better management of the effort and to the preservation of the energy so as to facilitate the restoration.

Keywords: effort, assessment, competitive result.

How to cite: Anton, M. (2018). Issues of Training Evaluation at Javelin Throwers. Revista Romaneasca pentru Educatie Multidimensionala, 10(1), 10-19. https://doi.org/10.18662/rrem/12 


\section{Introduction}

Athletics, within the broad meaning of effort, has social value that satisfies multiple specific valences from the formation of skill and motor skills, to meeting the edge, and to promoting the ideas of peace and friendship among people. "Sport performance is a strong educational factor directed not only towards physical excellence but to moral and aesthetic improvement as well" (Toma Urichianu, 2011).

\section{Problem Statement}

One of the purposes of this paper is to evaluate the means of training by control events and assess their outcome in competitions. The other is to measure the effort curve in the pre-competition period to enable a more complex analysis of the training effort in terms of volume, intensity, density and complexity. The results of this research can help give up redundant training and replace them with specific ones to improve future training plans. Better effort and redundancy management can lead to shorter preparation times and allow faster recovery with decisive implications for increased performance in the competition.

The aim of this research is to correlate both the key means used in competition with the results obtained in order to monitor physical training before the reference competition and to interpret the biological echo of the effort in different effort intensity areas, to better manage the time of preparation and recovery in order to improve and get the best result at the contest. "Each of these major informations clearly shows just how much sport has changed over the last fifteen years, and why it is now essential to have a highly trained staff to ensure a successful outcome." (Dominteanu, 2009). Adaptation strategies must be used in order to optimize the sport performance, due to the hard condition appropriate to the sport competition which can differ in intensity in relation to the physical capacity of the athlete, with his competitive experience and ambition level" (Dominteanu, 2015).

In high performance, from a physiological perspective, effort parameters are required at maximum values. Our opinion is that future growth in performance will be due to psychology. "The right relationship between exercise effort and the interval between more workouts is an essential condition for increasing training efficiency. Time too short for rest does not allow the general capacity to be restored and reduces performance." (Smîdu, 2014). The evaluation is diverse and even contradictory. 
In our opinion, the assessment must have at least three criteria: fidelity, meaning, and practicability. "The periodicity of the training program also helps identifying stages of training at age-level to achieve sport performance." (Stan, 2014). A complex evaluation of the training involves a pedagogical, biomechanical, biological, psychological, and methodological. State-of-the-art training methods and means can be designed already tailored on athletes functional potential, to meet excellence as soon as the training stages are completed" (Toma Urichianu, 2011).

\section{Aims of the research}

If the means used in the preparation of high-performance javelin throwers are those appropriate to the training periods, then the results of the competition echo the made effort.

\section{Research Methods}

The application was carried out in the precompetitive season, prior to the National Winter and Summer Championship of 2016, during the national training period, having as subjects, four of Romania's best javelin athletes.

From the training records of athletes and coaches we considered the results of the control events, as a monthly test of the main specific and nonspecific means of preparation. These control events were: speed running, standing start on 30ms.p (s) and 50mms.p (s), measured in seconds; jumps on the spot: length l.f.., triple f.el. and leap penta, measured in meters and strength tests: squats, snapped and pulled to the chest and throwing weight: forward (A.G., 7kg) and backward (A. Gr. Back, 7kg), which is measured in kilograms. From two attempts, we recorded the best results and the correlation index to the best throw in the contest.

To test the level of physical training in the pre - competition summer period. To test the level of physical training, we used the "Polar Team ${ }^{2}$ " software in a strength training session for approximately one hour and 20 minutes (1.22.20, see charts), which is designed specifically for effort intensity management (five areas of effort) and the biological echo of effort indicators (minimum, maximum and average heart rate, kilocalories) that provided real-time information. The Polar Team ${ }^{2}$ includes: base station, transmitter charger, 10 rechargeable transmitters and Team² Wear Link + straps, USB drive and PC and PDA software. 


\section{Findings}

- Results of the control events, the result of the National Long Javelin Throwing (Winter) National Championship Contest and the Correlation Index Calculation

Table no. 1.

\begin{tabular}{l|llllllllll}
\hline $\begin{array}{l}\text { Nr.of } \\
\text { subjec } \\
\text { ts. }\end{array}$ & 1 & 2 & 3 & 4 & 5 & 6 & 7 & 8 & 9 & $\begin{array}{l}\text { Com } \\
\text { result } \\
\text {. }\end{array}$ \\
\hline 1. & 3.80 & & 3.40 & 8.70 & & 90 & 140 & & & 71.88 \\
2. & 3.54 & 5.40 & 3.06 & 8.90 & 15.45 & 110 & & 15.40 & 17.23 & 67.90 \\
3. & 3.52 & 8.82 & 3.17 & 8.82 & & & 160 & 15.90 & 16.80 & 71.90 \\
4. & 3.80 & & 3.07 & & & 95 & 165 & & & 72.06 \\
\hline
\end{tabular}

- Results of the control events, the result of the National Summer Championship and the calculation of the correlation index

Table no. 2.

\begin{tabular}{l|llllllllll}
\hline $\begin{array}{l}\text { Nr.of } \\
\text { subje } \\
\text { cts }\end{array}$ & 1 & 2 & 3 & 4 & 5 & 6 & 7 & 8 & 9 & $\begin{array}{l}\text { Com. } \\
\text { rezult }\end{array}$ \\
\hline 1. & 3.58 & & 3.54 & 8.78 & & 92.5 & 145 & & & 74.85 \\
2. & 3.40 & 5.30 & 3.00 & 9.15 & 16.02 & 115 & 165 & 15.56 & 17.23 & 73.98 \\
3. & 3.48 & & 3.10 & 9.10 & & 120 & 180 & & & 69.30 \\
4. & 3.60 & & 3.20 & 8.60 & & 100 & 175 & & & 73.80 \\
\hline
\end{tabular}

Legend: Sprint crouch start, $30 \mathrm{~m}$ (seconds) 2. Sprint standing start $50 \mathrm{~m}$ (seconds); 3-long jump without dash (m); 4-triple jump without dash(m); 5-penta jump without dash; 6. Weightlifts snatch $(\mathrm{kg}) ; 7$. Weightlifts - squats $(\mathrm{kg}) ;$ 8-Throwing weight forward $4 \mathrm{~kg}$; 9Reverse weight throwing $4(\mathrm{~kg})$.

- Correlation Matrix for Winter Results

Table no. 3.

\begin{tabular}{llllllll}
\hline & $\begin{array}{l}30 \mathrm{~m} \\
(\mathrm{~s})\end{array}$ & $\begin{array}{l}50 \mathrm{~m} . \\
(\mathrm{s})\end{array}$ & $\begin{array}{l}\text { Long } \mathrm{j} . \\
(\mathrm{m})\end{array}$ & $\begin{array}{l}\text { Snatch } \\
(\mathrm{kg})\end{array}$ & $\begin{array}{l}\text { Squats } \\
(\mathrm{kg})\end{array}$ & $\begin{array}{l}\text { Th.for } \\
4(\mathrm{~kg})\end{array}$ & $\begin{array}{l}\text { Th rev } \\
4(\mathrm{~kg})\end{array}$ \\
\hline $30 \mathrm{~m}(\mathrm{~s})$ & 1 & & & & & \\
$50 \mathrm{~m}(\mathrm{~s})$ & -0.96 & 1 & & & & \\
Long $\mathrm{j} .(\mathrm{m})$ & 0.42 & -0.32 & 1 & & & \\
snatch $(\mathrm{kg})$ & 0.48 & -0.70 & -0.10 & 1 & & \\
Squats $(\mathrm{kg})$ & 0.49 & -0.23 & 0.36 & -0.51 & 1 & \\
\hline
\end{tabular}




\begin{tabular}{lccccccc}
\hline $\begin{array}{l}\text { Th for. } \\
\text { 4kg. }\end{array}$ & -0.99 & 0.95 & -0.43 & -0.45 & -0.51 & 1 & \\
$\begin{array}{l}\text { Th.rev. } \\
\text { 4kg. }\end{array}$ & -0.99 & 0.94 & -0.44 & -0.41 & -0.54 & 0.99 & 1 \\
Result & 0.54 & -0.29 & 0.45 & -0.46 & 0.99 & -0.57 & -0.60 \\
\hline
\end{tabular}

- Correlation matrix for summer result

Table no. 4.

\begin{tabular}{|c|c|c|c|c|c|c|c|}
\hline & $\begin{array}{r}30 \mathrm{~m} . \\
\text { (s) }\end{array}$ & $\begin{array}{l}50 \mathrm{~m} . \\
(\mathrm{s})\end{array}$ & $\begin{array}{l}\text { Long } \\
\text { j. }(\mathrm{m})\end{array}$ & $\begin{array}{l}\text { Snach } \\
(\mathrm{kg})\end{array}$ & $\begin{array}{l}\text { Squats } \\
(\mathrm{kg})\end{array}$ & $\begin{array}{l}\text { Th.for. } \\
\text { (4kg) }\end{array}$ & $\begin{array}{l}\text { Th. } \\
\text { rev } \\
(4 \mathrm{~kg})\end{array}$ \\
\hline $30 \mathrm{~m}(\mathrm{~s})$ & 1 & & & & & & \\
\hline $50 \mathrm{~m}(\mathrm{~s})$ & -0.82 & 1 & & & & & \\
\hline Long & & & & & & & \\
\hline $\mathrm{j} .(\mathrm{m})$ & 0.74 & -0.59 & 1 & & & & \\
\hline snatch $(\mathrm{kg})$ & -0.81 & 0.42 & -0.86 & 1 & & & \\
\hline Squats (kg) & -0.22 & -0.05 & -0.76 & 0.69 & 1 & & \\
\hline Th for. & & & & & & & \\
\hline $4 \mathrm{~kg}$ & -0.82 & 1 & -0.59 & 0.42 & -0.05 & 1 & \\
\hline $\begin{array}{l}\text { Th.rev. } \\
4 \mathrm{~kg}\end{array}$ & -0.82 & 1 & -0.59 & 0.42 & -0.05 & 1 & 1 \\
\hline Result & 0.29 & 0.26 & 0.45 & -0.75 & -0.72 & 0.26 & 0.26 \\
\hline
\end{tabular}

In the winter in the matrix above, we correlate $30 \mathrm{~m}$ with: (1) with 50m.p. (-0.9) by throwing weight forward A.G. Ahead(7kg) (-0.9) and throw back (A.K. back (7kg) (-0.99), with a snap between them.) Correlated: Length without dash, Chest pull (0.6) with pulling, squats correlate with throwing weight forward, throwing back weight, pulling to the chest and the result. There is a strong intensity link between the $30 \mathrm{~m}$ and $50 \mathrm{~m}$ event, the correlation ratio of -0.96 ; The minus sign indicates that the link is reverse in the sense that obtaining a good result in the $30 \mathrm{~m}$ sample involves a weaker result in the $50 \mathrm{~m}$ event. There is a close statistical correlation between $30 \mathrm{~m}$ event and the forward and backward weight throwing tests, ratio of -0.99 , but the link is reverse in the sense that for an athlete, better test results at 30 $\mathrm{m}$ will induce lower performance results in forwards or backwards weight throwing events.

There is a direct statistical link of average intensity between $30 \mathrm{~m}$ event and the overall result obtained in the contest, the correlation ratio of 0.54 . 
In the summer result in the above matrix in the first column we correlate: $30 \mathrm{~m} . . s j$ (1) to $50 \mathrm{~m} . s . j . ~(-0.8)$, length without dash (1.f.el.) (0.74) with pulling and throwing back weight (-0.82); length without dash (1) with pullout $(-0.86)$, squats $(-0.76)$, backward weight throwing $(-0.59)$ with chest pull $(-0.92)$ and result (-0.75); Chest pull squats (0.93).

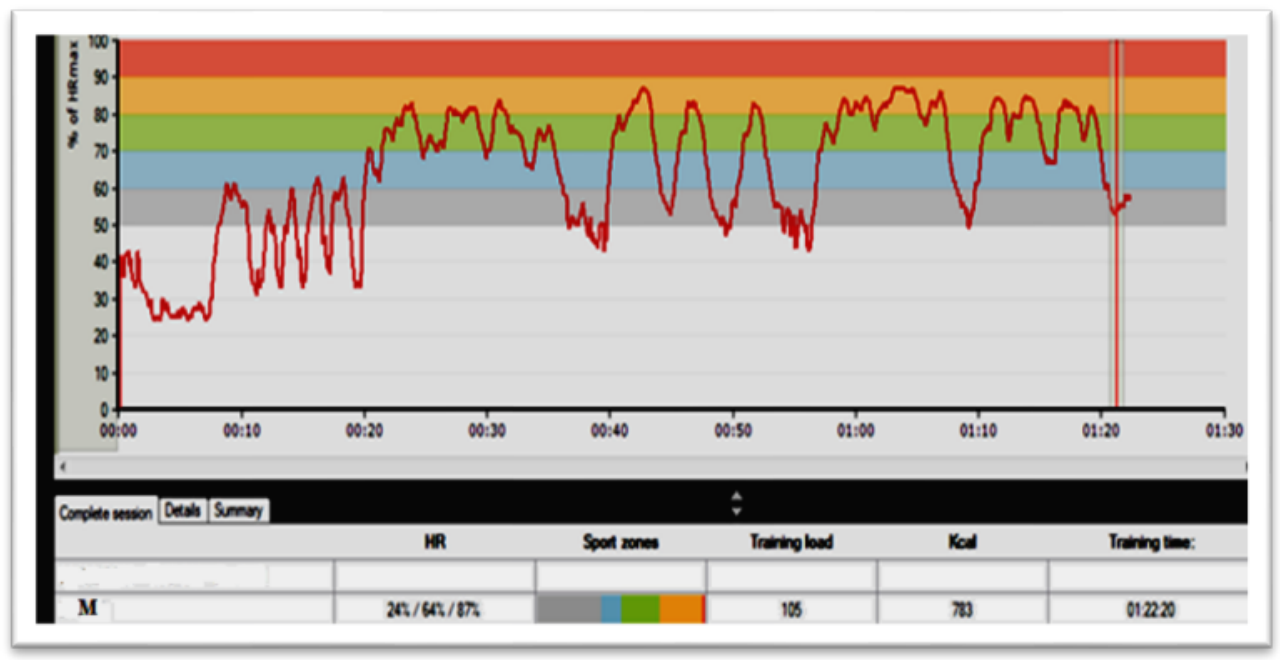

Figure No.1. Chart of the M javelin thrower

As seen in the chart above, $\mathrm{M}$ javelin thrower does not reach the area of maximum effort $(90-100 \%)$ but remains in the area of the submaximal effort (80-90\%), whose duration after C. Bota (2000) must be less than $1 \mathrm{~min}$; $\mathrm{M}$ javelin thrower remains in this area 15 minutes total of higher or lower intensity and sometimes even constant (see orange area, between $80-90 \%$ ).

The next area, of high intensity, takes more training time (see green area, between $70-80 \%$ ), that is longer than 6 minutes, after C. Bota (2000). The white and grey areas of the first 20 minutes correspond to body's preparation for the effort. From the effort intensity perspective, $M$ javelin thrower, in the chart above, is in normal parameters for the pre-competitive period. Consumption of Kcal is 783 with an average heart rate of $64 \%$ and $87 \%$ maximum of the submaximal effort. 


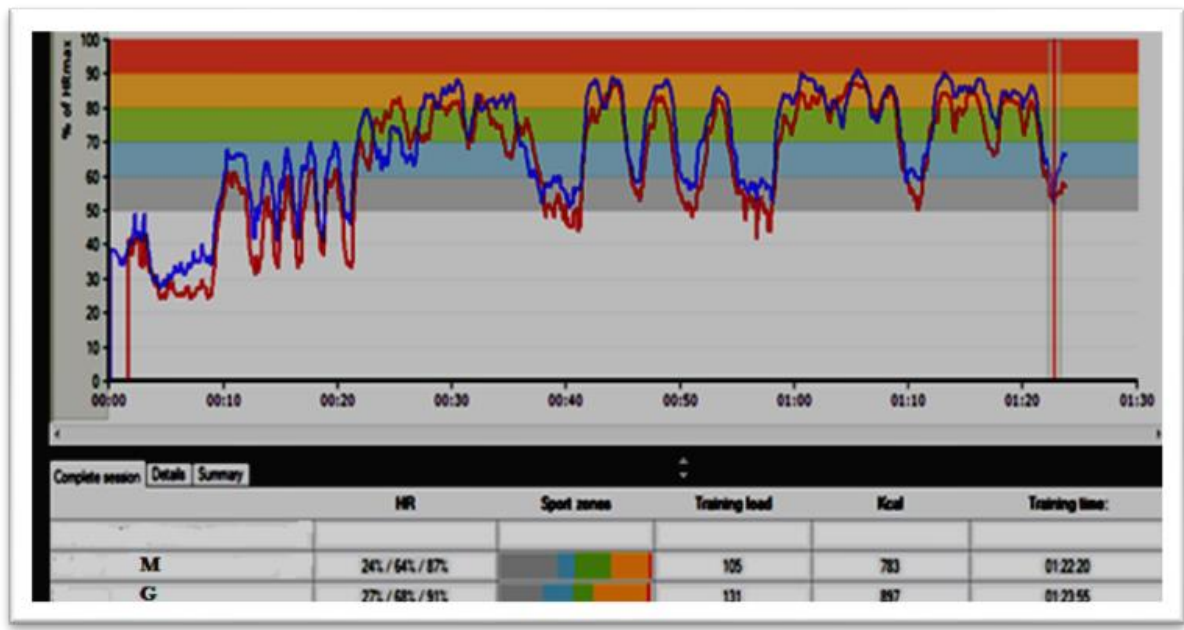

Figure No.2. The comparison of chart $M$ javelin thrower to $G$ javelin thrower $(M$, represented in red and $G$ in blue)

From the above compared chart, we can observe a consistence of the curves in the effort zones. However, $G$ javelin thrower seems more trained, because the body effort training curve is more abrupt and the total training performed in the submaximal intensity area is 50 minutes longer (see Spot zones) 20 minutes higher than that of M javelin thrower.

For this effort $G$ javelin thrower spends $897 \mathrm{kcal}$ versus $783 \mathrm{M}$ javelin thrower and has also a higher heart rate, that is 68 versus $64 \%$ and maximum 91 versus $87 \%$ of $\mathrm{M}$ javelin thrower.

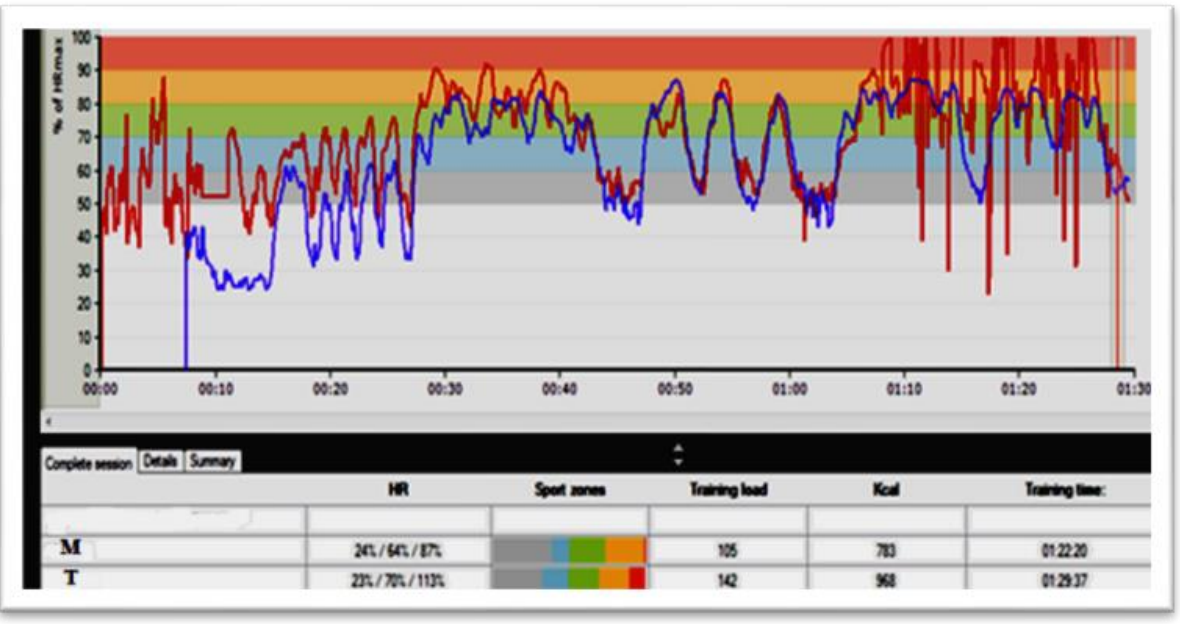

Figure No.3. The comparison of diagram $M$ javelin thrower to $T$ javelin thrower $(\mathrm{M}$, represented in blue and $\mathrm{T}$ in red) 
What is most interesting to observe is the above compared chart where $\mathrm{M}$ javelin thrower does a traditional warm-up, progressively overloading his body to effort whereas $\mathrm{T}$ javelin thrower does a different warm-up overloading, in 5 minutes reaching the submaximal effort zone, then lowers intensity and does a traditional warm-up but at a higher effort zone. $T$ javelin thrower reaches the maximum effort zone and above, but the recovery period is in the $20-30 \%$ range. The above aspect highlights the different way of approaching the effort or rather different parameters (volume, intensity, density, complexity) using similar means.

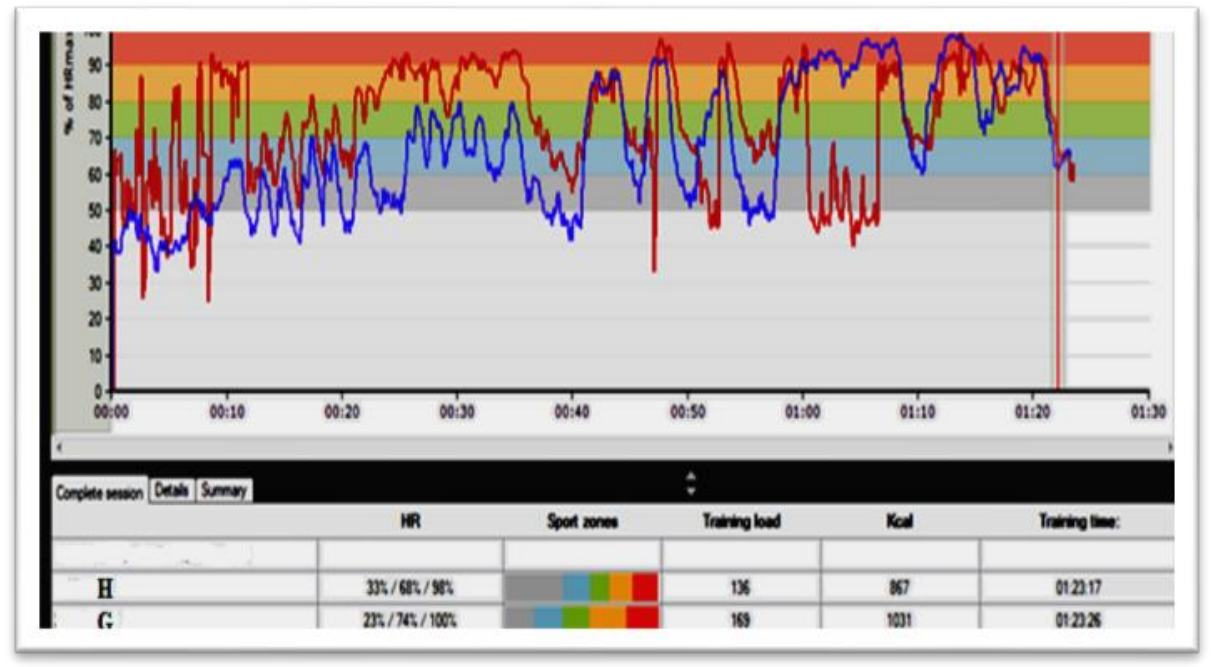

Figure No.4. The comparison chart (H javelin thrower, represented graphically above in red and $G$ javelin thrower in blue)

And in the above chart, initially there can be a different warm-up in which the $G$ javelin thrower manages to reach the submaximal and maximum parameters in the first 35 minutes; Then a fall or an active return of five minutes; then it oscillates again in the submaximal maximal areas, after which he returns to the $40-50 \%$ area for almost 10 minutes, that is between $1 \mathrm{~h}$ $1 \mathrm{~h} 10 \mathrm{~min}$, when he finally recovers. Energy consumption is higher, of $1031 \mathrm{kcal}$ compared to $867 \mathrm{kcal}$ of $\mathrm{H}$ javelin thrower. The sustained effort range of 70$100 \%$ is considerably higher in favor of $\mathrm{G}$ javelin thrower, which allows us to assert that his physical training is superior.

\section{Discussions}

While at the maximum effort, the required energy system is anaerobic and the energetic substrate is represented by phosphate, at the 
sub-maximal effort, the energogenesis is also anaerobic, but the energetic substrate is more complex, that is, besides ATP and PC, the carbohydrates are degraded by anaerobic glycolysis resulting in lactic acid (Bota, 2000). Lactic acid production leads to muscle fatigue. Training load also shows the workout intensity or toughness.

If the numbers are below 100, this means that the training is below the potential of the athlete, and this can be seen from the first chart where the intensity of the effort was submaximal over a 15 minutes period, while at other athletes the training toughness was over the potential but also the corresponding effort ran in the maximum and submaximal range for longer durations, i.e., 30-50 minutes. "In physical exercise planning, warm-up activities are followed by exercises to improve strength and the movement sectors, by cardio resilience activities, simulating sports and stretching exercises." (Stan, 2013).

\section{Conclusions}

The training of javelin throwers, although seemingly the same, differs in the means of training, both in their number and diversity, and in the characteristics of the effort. Control events may reflect the level of general physical training, or the level of specific training.

Correlated control events can be eliminated and control events that correlate with the result of the contest can show that obtaining a good result in these events can predict a good result in the competition. Removing redundant means, while keeping the specifics and maximizing the intensity of the effort to that characteristic of the competition, would create time for recovery that would lead to the improvement of the neuro-muscular freshness needed for this type of throw, followed by a relevant outcome in the competition.

Power training monitored with the help of the Polar Team ${ }^{2}$, divided into five areas of effort, has a different biological echo, which shows that the degree of training is not the same for the four javelin throwers and their approach to the effort characteristics differ within the same type of training, by different use of volume, intensity, density and complexity characteristics.

\section{References}

Bota, C. (2000). Ergofiriologie. Bucuresti: Editura Globus.

Dominteanu, T. (2009). Sports management and his important role in professional practice. Metalurgia international - sustainability quality leaderschip, 6, 63. 
Dominteanu, T., Smidu, N., \& Voinea, A. (2015). Coping - strategies of adaptation to competitive stress. Presented at International Conference Lumen Rethinking Social Action. Core values-RSACV, 2015.

Smîdu, N. (2014). The Recovery-an essential condition for optimizing the performance capacity. Indian Journal of Applied Research (IJAR), IV(XI), 457-459.

Stan, E.A. (2013). Refacerea ortopedica prin terapia acvatica. Bucuresti: Editura Didactica si Pedagogica.

Stan, E. A. (2014). Performanța sportivă în înotul sincron programe de pregătire - metodica predării înotului sincron. Editura Printech, Bucureşti. p. 7

Toma Urichianu, S. (2011). Study on the evaluation of the level of training for the 18 months remaining for the rowers participating at 2012 London Olimpics case study national championship on ergometer, seniors. Presented at the Ovidius University of Constanta, „Perspectives in Physical education and sport" International Scientific Conference.

Toma Urichianu, S. (2011). For major contribution in the domain of physical education and university sport. Presented at the „Education through sport-sport for health", the International Session of Scientific Communications.. University of Bucharest: Editura Bren. pp. 175178. 